Article

\title{
Enhanced Microwave Absorption Bandwidth in Graphene-Encapsulated Iron Nanoparticles with Core-Shell Structure
}

\author{
Danfeng Zhang ${ }^{1, *}$, Yunfei Deng ${ }^{2}$, Congai Han ${ }^{2}$, Haiping Zhu ${ }^{2}$, Chengjie Yan ${ }^{2}$ and \\ Haiyan Zhang ${ }^{2, *}$ \\ 1 School of Computer Science and Technology, Guangdong University of Technology, \\ Guangzhou 510006, China \\ 2 School of Materials and Energy, Guangdong University of Technology, Guangzhou 510006, China; \\ dyf1012gdut@163.com (Y.D.); hca0109gdut@163.com (C.H.); HpZhu321@163.com (H.Z.); \\ Richaryan@163.com (C.Y.) \\ * Correspondence: dfzhang@gdut.edu.cn (D.Z.); hyzhang@gdut.edu.cn (H.Z.)
}

Received: 6 April 2020; Accepted: 6 May 2020; Published: 12 May 2020

\begin{abstract}
Graphene-encapsulated iron nanoparticles $(\mathrm{Fe}(\mathrm{G}))$ hold great promise as microwave absorbers owing to the combined dielectric loss of the graphene shell and the magnetic loss of the ferromagnetic metal core. Transmission electron microscopy (TEM) revealed transition metal nanoparticles encapsulated by graphene layers. The microwave electromagnetic parameters and reflection loss $(\mathrm{R})$ of the $\mathrm{Fe}(\mathrm{G})$ were investigated. Graphene provided $\mathrm{Fe}(\mathrm{G})$ with a distinctive dielectric behavior via interfacial polarizations taking place at the interface between the iron cores and the graphene shells. The $\mathrm{R}$ of $\mathrm{Fe}(\mathrm{G})$ /paraffin composites with different $\mathrm{Fe}(\mathrm{G})$ contents and coating thickness was simulated according to the transmit-line theory and the measured complex permittivity and permeability. The $\mathrm{Fe}(\mathrm{G}) /$ paraffin composites showed an excellent microwave absorption with a minimum calculated $\mathrm{R}$ of $-58 \mathrm{~dB}$ at $11 \mathrm{GHz}$ and a $60 \mathrm{wt} \% \mathrm{Fe}(\mathrm{G})$ loading. The composites showed a wide bandwidth (the bandwidth of less than $-10 \mathrm{~dB}$ was about $11 \mathrm{GHz}$ ). The $\mathrm{R}$ of composites with 1-3 mm coating thickness was measured using the Arch method. The absorption position was in line with the calculated results, suggesting that the graphene-coated iron nanoparticles can generate a suitable electromagnetic match and provide an intense microwave absorption. Excellent $\mathrm{Fe}(\mathrm{G})$ microwave absorbers can be obtained by selecting optimum layer numbers and Fe(G) loadings in the composites.
\end{abstract}

Keywords: microwave absorption; graphene-encapsulated iron nanoparticles; permittivity and permeability; simulation; reflection loss

\section{Introduction}

With the rapid development of electronic and wireless technologies, electromagnetic interference (EMI) and pollution are becoming serious issues worldwide, affecting more and more electronic integrated devices and the living environment [1,2]. In order to solve these ever-growing serious environment issues, absorbing materials are required to present a number of characteristics (e.g., wide absorption bandwidths, intense absorption, lightweight, and low thickness), the so-called "thin, light, wide, and strong" requirements. Therefore, electromagnetic absorption materials with wide bandwidth, high absorption rate, and tunable electromagnetic properties have been increasingly favored by researchers [3,4]. Among these materials, it is particularly important that the new microwave absorbing materials have appropriate overall performance $[5,6]$. Ferromagnetic metals and their oxides are well-known for having excellent magnetic loss absorbance [7,8]. However, the chemical instability 
and heavy mass of ferromagnetic metals in air hinder their potential application as microwave absorbers. Owing to its oxidation resistance, carbon has been proposed as an ideal protective layer material for metals, especially metal nanoparticles [9-12]. Carbon-based materials also present good dielectric loss along with light weight and broadband microwave absorption. A new nano-structured composite microwave absorption materials such as carbon-encapsulated metal nanoparticles have been found to present improved electromagnetic absorption and tunable electromagnetic properties. This material consisted of a metal nanoparticle inner core and a carbon outer shell. Materials of the carbon shells include graphite [13], amorphous carbon [14], and graphene [15], while metals include $\mathrm{Ni}$ [14], Co [16], FeNi [17], FeCo [18], FeSn 2 [19], and $\mathrm{TiO}_{2}$ [20], among others. As we all know, controlling the composition and structure of the composite core and shell can make the dielectric and magnetic properties of these materials more conducive to impedance matching [21]. The dielectric and surface chemistry characteristics of carbon make it a promising shell material for nanoparticles $[18,22,23]$. Carbon-encapsulated metal nanoparticle structure composite materials present numerous advantages, including wide electromagnetic absorption bandwidth, low density, and stable physical and chemical properties [24]. This outer nanocarbon shell prevents the inner nanometallic particles from oxidation and agglomeration, and the core-shell structure is also conducive to the impedance matching of the enclosed space. As a result, this material showed improved electromagnetic wave absorption properties [25]. Previous reports revealed (Fe, Ni)/C nanocapsules to have improved electromagnetic wave absorption upon proper core composition design and good electromagnetic match [17]. The presence of heterogeneous interfaces and the distinctive core-shell structure increased the number of surface anisotropies and reduced the eddy current in (Fe, $\mathrm{Ni}) / \mathrm{C}$ as compared with their metal and alloy counterparts. Owing to the unique core-shell structure of the nanoparticles, the electromagnetic field was coupled to the metal magnetic core and the dielectric shell, thus the core-shell structured nanoparticles showed an obviously improved impedance match [26,27].

Core-shell nanostructures have shown excellent electromagnetic properties and microwave absorption characteristics compared with single metal or pure carbon materials [28]. Liu et al. [29] prepared carbon-encapsulated FeNiMo alloy nanoparticles. The excellent electromagnetic properties of this material were the result of the highly complex magnetic permeability and good impedance matching of the FeNiMo core nanoparticles. Zhang et al. [16] discovered multi-dielectric polarizations when studying the wave-absorbing properties of core-shell graphite-coated cobalt nanoparticles. These dielectric polarizations originate from the highly polarized graphite shell and core-shell interface polarization. Liu et al. [30] studied electromagnetic wave absorption properties of $\mathrm{FeNi}_{3}$ nanoparticles coated with graphite shells and found that graphite shells increased the magnetic/dielectric loss and attenuation constant of carbon-coated $\mathrm{FeNi}_{3}$ nanoparticles and coatings. The core-shell structured carbon-encapsulated metal nanoparticles have shown superior electromagnetic properties compared with traditional absorbers. However, the preparation of thin materials combining high-efficiency microwave absorption and a wide effective bandwidth remains highly challenging, and the electromagnetic loss mechanism of core-shell structured nanoparticles requires further studies. In terms of this view, graphene is a new nanocarbon material that can be used for this purpose. Jian et al. [31] successfully prepared nanoscale $\mathrm{Fe}_{3} \mathrm{O}_{4}$ /graphene capsule (GC) composites. The microwave-absorbing characteristics of the as-prepared composites showed a minimum reflection loss (R) of $-32 \mathrm{~dB}$ at 8.76 GHz and an $\mathrm{R}$ lower than $-10 \mathrm{~dB}$ for an absorption bandwidth of 5.4-17 GHz. The electromagnetic absorption characteristics of graphene-encapsulated magnetic metal nanoparticles have been scarcely studied. $\mathrm{Fe}(\mathrm{G})$ materials are largely unexploited despite that they can present a better match between $\varepsilon$ and $\mu$ than iron absorbers. In this article, we reported simulated and actual measured $R$ values of $F e(G)$ and compared these values with those previously published (mostly calculated results). As detailed herein, the lower $\mathrm{R}$ value of $\mathrm{Fe}(\mathrm{G})$ over a wide frequency range can be achieved by optimizing the thickness of the coating material and the concentration of the $\mathrm{Fe}(\mathrm{G})$. The electromagnetic characteristics of the $\mathrm{Fe}(\mathrm{G})$ were investigated by measuring the electromagnetic parameters of the $\mathrm{Fe}(\mathrm{G}) / \mathrm{paraffin}$ composites. We calculated the $\mathrm{R}$ of $\mathrm{Fe}(\mathrm{G}) /$ paraffin composites with different $\mathrm{Fe}(\mathrm{G})$ concentrations 
and sample thicknesses (1-3 mm). Experimental R measurements were conducted over Fe(G)/epoxy coatings and the results were compared with the calculated $R$ values.

\section{Experimental}

The $\mathrm{Fe}(\mathrm{G})$ nanoparticles were prepared by an arc discharge method in our laboratory [32]. The arc discharge was generated by applying a direct current of $150 \mathrm{~A}$ at $60 \mathrm{~V}$ between two electrodes at an argon pressure of $10 \mathrm{kPa}$. The distance between the electrodes was 3-4 mm. A graphitic and iron powder of micron size $(\mu \mathrm{m})$ was used as a raw material. The mixture was shaped in form of cylindrical anode of $25 \mathrm{~mm}$ in diameter and $50 \mathrm{~mm}$ in height. This anode was consumed and produced soot during the arc discharge process. This soot was deposited on the inner surface of the reaction chamber. After the arc discharge reaction, the soot was collected and $\mathrm{Fe}(\mathrm{G})$ nanoparticles samples were obtained.

The microstructure of the $\mathrm{Fe}(\mathrm{G})$ nanoparticles was characterized by transmission electron microscopy (TEM, Talos F200S *, Brno, Czech Republic), Raman spectroscopy (Raman, LabRAM HR Evolution type, HORIBA Jobin Yvon, Paris, France), and X-ray diffraction (XRD, D8 Advance type, Germany Bruker Co. Bavaria, Germany). X-ray photoelectron (XPS, Escalab 250Xi type, Thermo Fisher, Massachusetts, America) was used to study the phase composition of the samples and the bond structure of the graphene shells.

$\mathrm{Fe}(\mathrm{G})$ and paraffin were mixed in a mechanical mixer at $140{ }^{\circ} \mathrm{C}$ to melt the paraffin, and thus achieve homogenous dispersion of $\mathrm{Fe}(\mathrm{G})$. The paraffin is an electrical insulator (melting temperature: $92{ }^{\circ} \mathrm{C}$ ) of nonmagnetic material transparent to electromagnetic waves [33]. The mixture was pressed through a mold into a ring-shaped sample with a thickness of 2-3 $\mathrm{mm}$ for the EM wave measurement. The relative permittivity and permeability were obtained by the AV3618 Network Analyzer (Zhongdianke Instrument Co., Ltd. Qingdao, China).

$\mathrm{Fe}(\mathrm{G})$ nanoparticles were used as fillers, epoxy resin was used as matrix, and absolute ethanol was used as dispersion medium. $\mathrm{Fe}(\mathrm{G})$ nanoparticle slurry was dispersed in epoxy resin to prepare $\mathrm{Fe}(\mathrm{G})$ nanoparticle/epoxy resin mixture, and then these coating samples were coated on a $180 \mathrm{~mm} \times 180 \mathrm{~mm}$ standard aluminum plate to prepare the measured wave absorption coating. The measured $\mathrm{R}$ value was measured by using the arch method, which was one of the important parameters for evaluating the actual reflectance of the absorbing material [34,35]. The aluminum plate operating within $2-18 \mathrm{GHz}$ is considered a "perfect" reflection or $0 \mathrm{~dB}$ level (the reference level) material. Therefore, there was no substrate effect on the measured $R$ values.

\section{Results and Discussion}

\subsection{Characterization of $\mathrm{Fe}(\mathrm{G})$}

TEM images of Fe $(G)$ nanoparticles are shown in Figure 1. The Fe $(G)$ nanoparticles were 30-100 nm in diameter, with a wide size distribution (Figure 1a). The $\mathrm{Fe}(\mathrm{G})$ nanoparticles showed a spherical morphology and a core-shell structure, with the inner iron core being completely encapsulated by the outer graphene shells. High-resolution TEM (HRTEM, Figure 1b) revealed outer graphene shells of ca. 2-2.5 nm in thickness (ca. 5-7 graphitic layers with a distance of $0.34 \mathrm{~nm}$ each layer). Carbon-coated metal nanocapsules with carbon shells of 5-6 $\mathrm{nm}$ in thickness have been previously reported [14]. 

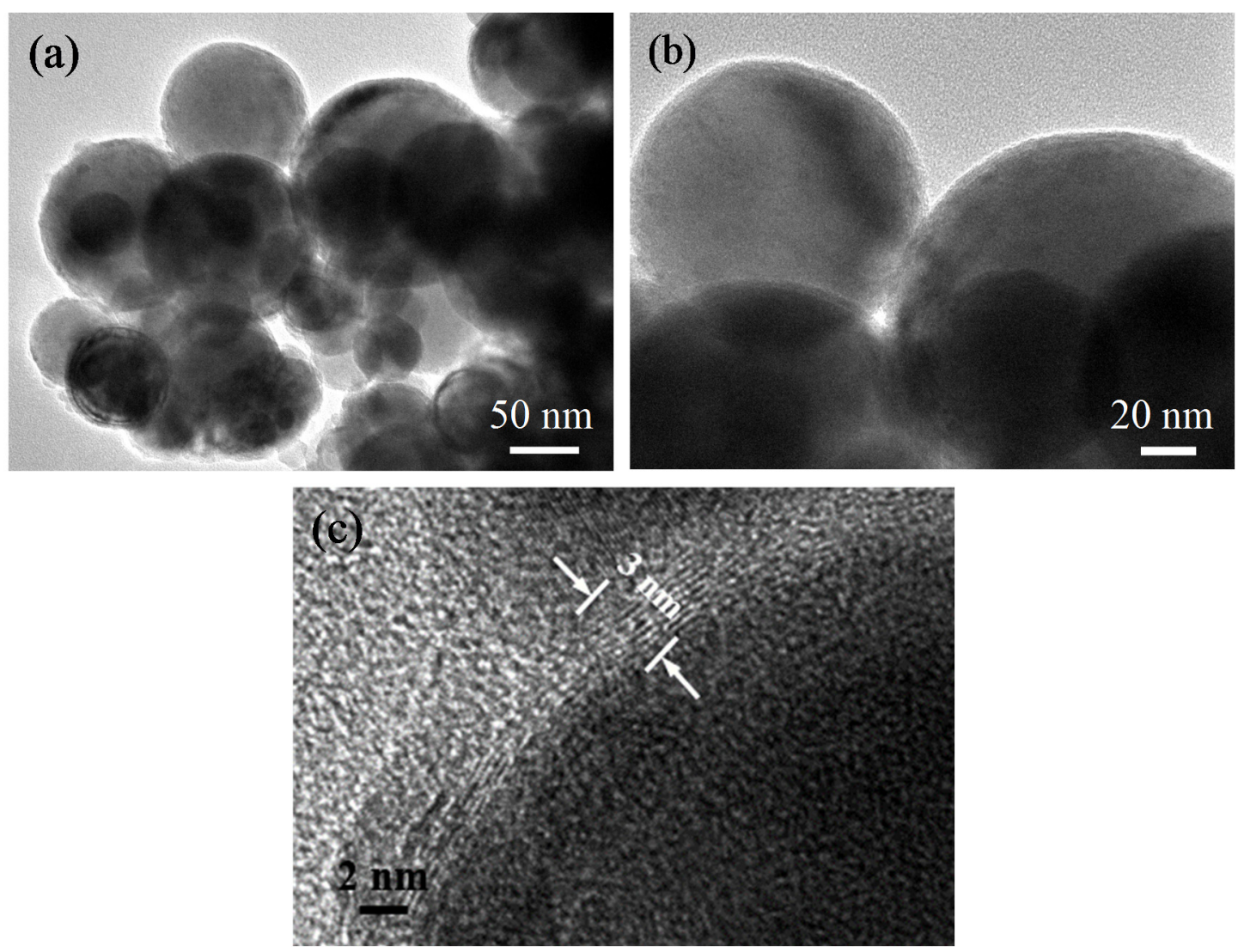

Figure 1. (a,b) Transmission electron microscopy (TEM) images, (c) high resolution TEM (HRTEM) image of $\mathrm{Fe}(\mathrm{G})$ nanoparticles.

The XRD pattern and the Raman spectrum of the $\mathrm{Fe}(\mathrm{G})$ nanoparticles are shown in Figure 2. $\mathrm{Fe}(\mathrm{G})$ showed iron and carbon diffraction peaks, and no diffraction peaks of iron oxides or iron carbide were identified. Thus, the Fe core in the $\mathrm{Fe}(\mathrm{G})$ nanoparticles remained reduced owing to the protective graphitic shell $[17,36]$. The TEM image shown in Figure 1 also confirmed the correctness of the XRD results. Three sharp peaks were observed in the XRD pattern corresponding to the (110), (200), and (211) planes of iron, respectively. These data confirmed that the inner iron core of $\mathrm{Fe}(\mathrm{G})$ nanoparticles possessed a high degree of crystallinity. The diffraction peaks of the (002) plane of graphene were very weak compared with the peak of Fe, which was not observed in the XRD pattern, and in line with previous works showing no detectable peaks of carbon $[17,21,37]$. The characterization of carbon species in carbon-based materials is usually identified by Raman spectroscopy. Raman spectra of carbon material usually exhibit two broad peaks at ca. $1350 \mathrm{~cm}^{-1}$ (D peak for 'disordered' carbon) and at $1580 \mathrm{~cm}^{-1}$ (G peak for 'graphite carbon'). Figure $2 \mathrm{~b}$ shows the Raman spectrum of the $\mathrm{Fe}(\mathrm{G})$ nanoparticles. The bands at $1347 \mathrm{~cm}^{-1}$ and $1578 \mathrm{~cm}^{-1}$ are characteristic spectra of carbon materials and can correspond to the $\mathrm{D}$ and $\mathrm{G}$ bands, respectively. This observation is consistent with previous reports [38] showing a defective graphitic layer in the Raman spectra of graphene. What is more, the Raman spectra of graphite powders are shown in Figure 2b. There are two prominent peaks at $1330 \mathrm{~cm}^{-1}$ and $1574 \mathrm{~cm}^{-1}$, and these correspond to the $D$ and $G$ bands, respectively. As we all know, the value of the $\mathrm{I}_{\mathrm{D}} / \mathrm{I}_{\mathrm{G}}$ ratio can be used to evaluate the degree of disorder. The $\mathrm{I}_{\mathrm{D}} / \mathrm{I}_{\mathrm{G}}$ value of graphite powders is 0.4244 . What is more, the $\mathrm{I}_{\mathrm{D}} / \mathrm{I}_{\mathrm{G}}$ value of graphite is 0.6887 in the sample of the $\mathrm{Fe}(\mathrm{G})$ nanoparticles and higher than that of graphite powders. The higher ratio means a lower degree of graphitization. 

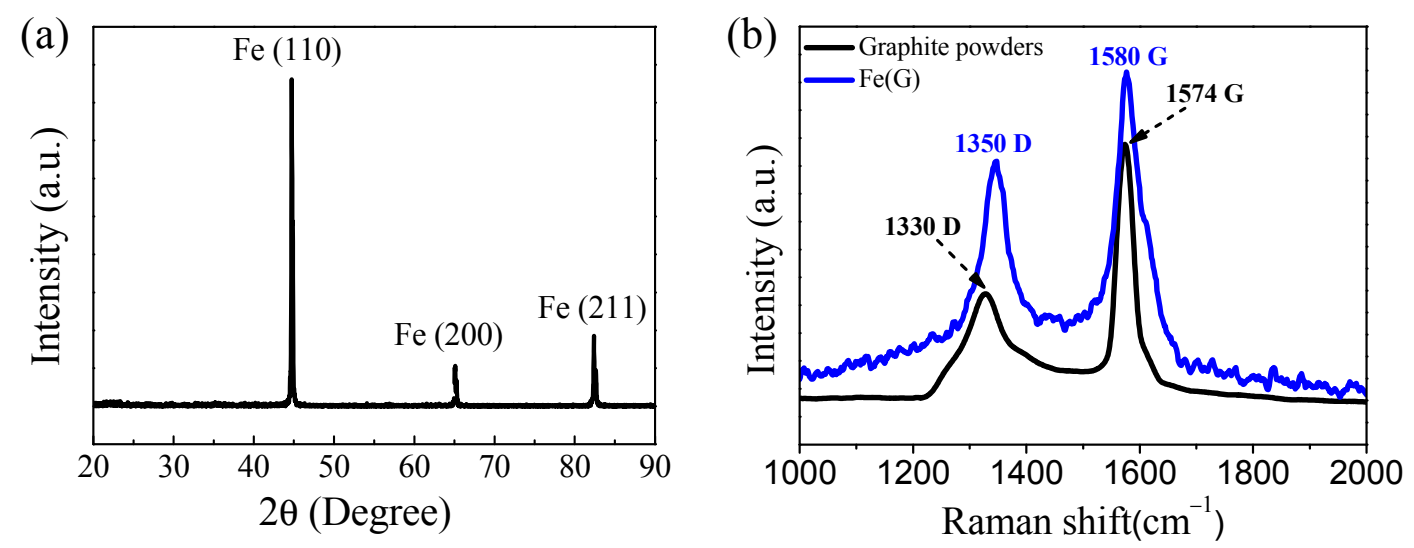

Figure 2. (a) X-ray diffraction (XRD) pattern and (b) Raman spectrum of $\mathrm{Fe}(\mathrm{G})$ nanoparticles and graphite powders.

In order to determine the surface composition of the $\mathrm{Fe}(\mathrm{G})$, XPS characterization was conducted. Figure S1 shows the C1s XPS spectra of the $\mathrm{Fe}(\mathrm{G})$ nanoparticles. The fitting curves revealed a $\mathrm{C}-\mathrm{C}$ binding energy of $284.6 \mathrm{eV}$, indicative of $\mathrm{C} 1 \mathrm{~s}$ electron of graphite on the surface [39]. We suggested that the peak at $283.6 \mathrm{eV}$ may correspond to the 1s electrons of graphite at the interface of graphene and $\mathrm{Fe}$ in the $\mathrm{Fe}(\mathrm{G})$ nanoparticles [40]. These observations were in line with the TEM results.

\subsection{Complex Permittivity of the Fe(G)/Paraffin Composites}

The real $\left(\varepsilon^{\prime}\right)$ and imaginary $\left(\varepsilon^{\prime \prime}\right)$ parts of the permittivity $(\varepsilon)$ of $\mathrm{Fe}(\mathrm{G}) /$ paraffin composites with $30 \mathrm{wt} \%, 40 \mathrm{wt} \%, 50 \mathrm{wt} \%$, and $60 \mathrm{wt} \% \mathrm{Fe}(\mathrm{G})$ loadings under 2-18 GHz are shown in Figure $3 . \varepsilon^{\prime}$ and $\varepsilon^{\prime \prime}$ both increased with the $\mathrm{Fe}(\mathrm{G})$ loading. $\varepsilon^{\prime}$ and $\varepsilon^{\prime \prime}$ reached maxima of 10.6 and 3.2, respectively, for the $\mathrm{Fe}(\mathrm{G}) /$ paraffin composite with a $60 \mathrm{wt} \% \mathrm{Fe}(\mathrm{G})$ loading. The $\mathrm{Fe}(\mathrm{G}) /$ paraffin composite with $50 \mathrm{wt} \%$ $\mathrm{Fe}(\mathrm{G})$ showed $\varepsilon^{\prime}$ and $\varepsilon^{\prime \prime}$ maxima at 8.4 and 2.5 , respectively. $\varepsilon^{\prime}$ decreased slightly as well as $\varepsilon^{\prime \prime}$ with the frequency, while the opposite trend was found for $\varepsilon^{\prime \prime}$. The peak of the $\varepsilon^{\prime \prime}$ curve appears at a local minimum, which is caused by polarization [18]. Because of the special core-shell microstructure of $\mathrm{Fe}(\mathrm{G})$ nanoparticles, Han et al. [18] also confirms the similarity between the dielectric constant spectra of carbon-coated FeCo materials. These pieces of evidence can provide a reasonable explanation for the dielectric constant curves observed in this paper. What is more, at high frequencies, dipole polarization played a major role, but at low frequencies, weak space charge polarization prevailed $[21,27,40]$. This is consistent with the previously reported $\mathrm{ZnO}$-coated iron nanoparticles [41] and carbon-coated iron nanocapsules [42]. The $\varepsilon^{\prime \prime}$ curves showed some broad dielectric relaxation peaks at ca. $6.0,8.5,11,13.5$, 15 , and $17.5 \mathrm{GHz}$ as a result of dielectric relaxation and polarizations. Interfacial polarizations taking place at the interface between iron cores and the graphene shells played a dominant role in determining the dielectric behaviour. As reported by Yan et al. [33], interfacial polarization of carbon-encapsulated $\mathrm{FeNi}_{3}$ resulted in strong dielectric losses. As previously reported [16,31,36], a relaxation process can also be generated in inner $\mathrm{Ni}, \mathrm{Co}$, and FeNi cores as a result of the enhanced electrical resistivity of the cores encapsulated by outer carbon shells. 
(a)

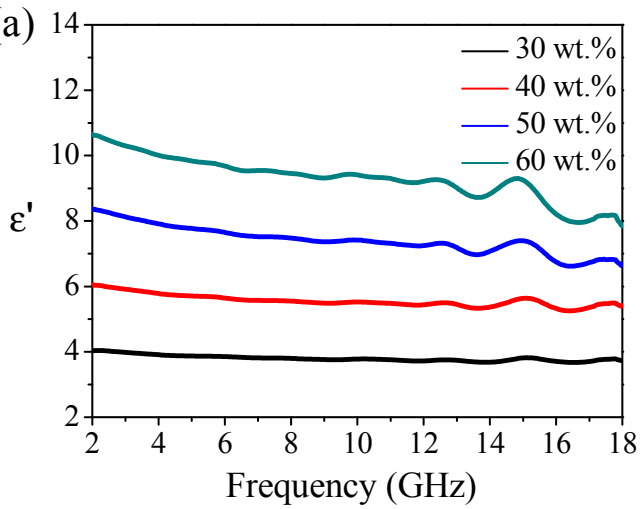

(b)

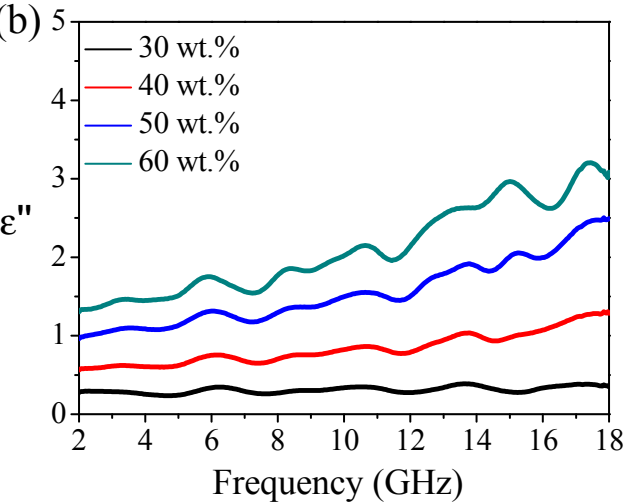

Figure 3. Real (a) and imaginary (b) parts of complex permittivity of $\mathrm{Fe}(\mathrm{G}) /$ paraffin composites under $2-18 \mathrm{GHz}$

\subsection{Complex Permeability of $\mathrm{Fe}(\mathrm{G}) /$ Paraffin Composites}

The real $\left(\mu^{\prime}\right)$ and imaginary $\left(\mu^{\prime \prime}\right)$ parts of permeability $(\mu)$ for $\mathrm{Fe}(\mathrm{G}) /$ paraffin composites with $30 \mathrm{wt} \%, 40 \mathrm{wt} \%, 50 \mathrm{wt} \%$, and $60 \mathrm{wt} \% \mathrm{Fe}(\mathrm{G})$ loadings under $2-18 \mathrm{GHz}$ are shown in Figure 4 . As shown in Figure $4 a, \mu^{\prime}$ decreased with the frequency over the entire frequency range. $\mu^{\prime}$ decreased from 1.30 , $1.42,1.54$, and 1.67 to $1.09,1.06,1.12$, and 1.18 under $2-18 \mathrm{GHz}$ for $30 \mathrm{wt} \%, 40 \mathrm{wt} \%, 50 \mathrm{wt} \%$, and $60 \mathrm{wt} \%$ $\mathrm{Fe}(\mathrm{G})$ loadings, respectively. While $\mu^{\prime \prime}$ exhibited a first increasing and then decreasing trend with an extremum value with increasing frequency, as shown in Figure $4 b, \mu^{\prime \prime}$ showed broad and low maxima at about $0.37,0.29,0.20$, and 0.14 under $8 \mathrm{GHz}$ for $60 \mathrm{wt} \%, 50 \mathrm{wt} \%, 40 \mathrm{wt} \%$, and $30 \mathrm{wt} \% \mathrm{Fe}(\mathrm{G})$ loadings, respectively. This observation is in good agreement with previous results on carbon-encapsulated FeCo nanoparticles with similar nanoparticle microstructures [18]. In view of the special core-shell structure of $\mathrm{Fe}(\mathrm{G})$ nanoparticles, the inner iron core was coated with graphene and separated from each other, so the direct exchange interaction between Fe cores could not be considered, and the dipole interaction was the main factor $[30,31]$. If there was no graphene shell to isolate the metallic Fe cores from each other, the direct contact of the metallic Fe cores would cause the eddy current to increase sharply while the value of $\mu^{\prime}$ decreases sharply [17]. In the case of $\mathrm{Fe}(\mathrm{G})$ nanoparticles, $\mu^{\prime}$ decreased and $\mu^{\prime \prime}$ remained at a nearly low value constant with frequency, revealing excellent insulation between the metallic iron cores [28]. Because $\mathrm{Fe}(\mathrm{G})$ particles are soft magnets with weak magnetic properties, hysteresis loss and domain wall displacement loss can be ignored. The main loss forms of hysteresis loss are hysteresis loss, eddy current loss, domain wall displacement, and natural resonance. Through the previous analysis, owing to the higher resistivity of $\mathrm{Fe}(\mathrm{G})$ nanoparticles and the presence of the graphene shell reducing eddy current losses, it can be inferred that the magnetic loss of $\mathrm{Fe}(\mathrm{G}) /$ paraffin composites was mainly natural resonance $[28,36]$.
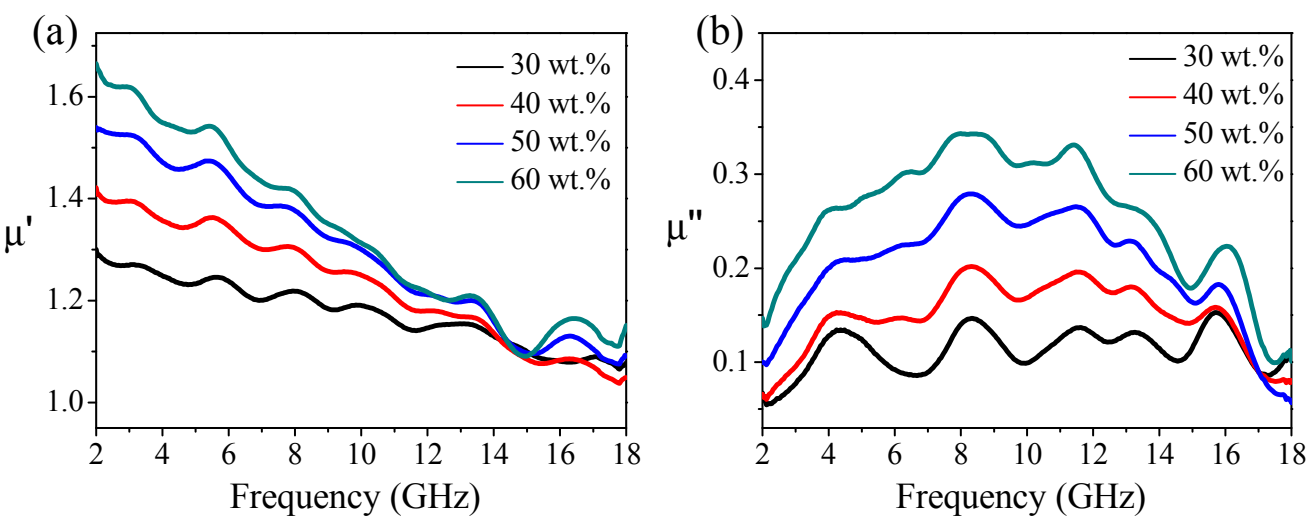

Figure 4. Real (a) and the imaginary (b) parts of complex permeability for $\mathrm{Fe}(\mathrm{G}) /$ paraffin composites under 2-18 GHz. 


\subsection{Calculated $R$ Values for $\mathrm{Fe}(\mathrm{G}) /$ Paraffin Composites}

We further investigated the electromagnetic wave absorption properties of the Fe $(\mathrm{G})$. According to the transmission line theory [43], the input impedance of the absorber layers is $Z_{\text {in }}(K),(K=1,2, \ldots, N)$. The input impedance of each layer can thus be calculated by the following formula, and the measured electromagnetic factor data were used to calculate the reflection loss $R\left(\right.$ or $R_{L}$ ):

$$
\begin{array}{r}
Z_{\text {in }}(K)=Z_{c}(K) \frac{Z_{\text {in }}(K-1)+Z_{c}(K) \tanh [\gamma(K) d(K)]}{Z_{c}(K)+Z_{\text {in }}(K-1) \tanh [\gamma(K) d(K)]} \\
R_{L}(d B)=20 \log \left|\frac{Z_{\text {in }}-1}{Z_{\text {in }}+1}\right|
\end{array}
$$

$\mathrm{Z}_{\mathrm{c}}(\mathrm{K})$ and $\gamma(\mathrm{K})$ can be calculated by Equations (3) and (4), respectively:

$$
\begin{gathered}
Z_{\mathrm{c}}(\mathrm{K})=\sqrt{\frac{\mu_{0} \mu_{\mathrm{r}}(\mathrm{K})}{\varepsilon_{0} \varepsilon_{\mathrm{r}}(\mathrm{K})}} \\
\gamma(\mathrm{K})=\frac{\mathrm{j} 2 \pi \mathrm{f}}{\mathrm{c}} \sqrt{\mu_{(\mathrm{K})} \varepsilon_{(\mathrm{K})}}=j \omega \sqrt{\varepsilon_{0} \mu_{0} \varepsilon_{\mathrm{r}}(\mathrm{K}) \mu_{\mathrm{r}}(\mathrm{K})} / \mathrm{c}
\end{gathered}
$$

where $\mathrm{Z}_{\mathrm{c}}(\mathrm{K})$ and $\gamma(\mathrm{K})$ are characteristic impedance and propagation constant for each layer, respectively; $c$ is the light speed; $\omega$ is the angular frequency; $\varepsilon_{0}$ and $\mu_{0}$ are the vacuum permittivity and the permeability, respectively; and $\varepsilon_{\mathrm{r}}(\mathrm{K})$ and $\mu_{\mathrm{r}}(\mathrm{K})$ are the relative permittivity and permeability of the K layer absorbing materials, respectively. According to the above formula of $\mathrm{R}$, the microwave absorption performance for $\mathrm{Fe}(\mathrm{G})$ /paraffin composites can be tuned by the measured electromagnetic factor data (permittivity and permeability).

Figure S2 shows the dependence of the calculated R with the frequency for a Fe $(G) /$ paraffin composite of $3 \mathrm{~mm}$ in thickness and with a $\mathrm{Fe}(\mathrm{G})$ loading of $40 \mathrm{wt} \%$. The calculated $\mathrm{R}$ values of $\mathrm{Fe}(\mathrm{G})$ nanoparticles, only graphene $(\mathrm{G})$, and only iron nanoparticles (Fe) are compared in Figure S2. The bandwidths of $\mathrm{R}<-10 \mathrm{~dB}$ were 2.6, 5.6, and $9.1 \mathrm{GHz}$ for $\mathrm{Fe}, \mathrm{G}$, and $\mathrm{Fe}(\mathrm{G})$, respectively. Thus, $\mathrm{Fe}(\mathrm{G})$ showed a wider bandwidth compared with Fe and $\mathrm{G}$ owing to suitable complementarities between the dielectric and magnetic losses.

Figure 5 shows the dependence of the calculated $R$ with the frequency for a $\mathrm{Fe}(\mathrm{G}) / \mathrm{paraffin}$ composite of 1-3 mm in thickness with different $\mathrm{Fe}(\mathrm{G})$ loadings of $30 \mathrm{wt} \%$, $40 \mathrm{wt} \%$, $50 \mathrm{wt} \%$, and $60 \mathrm{wt} \%$, respectively. The $\mathrm{R}$ of the composite of $1 \mathrm{~mm}$ in thickness was large. The composite of $2 \mathrm{~mm}$ in thickness showed a minimum $\mathrm{R}$ value, and this minimum was found to remarkably shift towards low frequencies from 18 to $11 \mathrm{GHz}$ upon increasing the $\mathrm{Fe}(\mathrm{G})$ loading from $30 \mathrm{wt} \%$ to $60 \mathrm{wt} \%$. The bandwidth of $\mathrm{R}<-10 \mathrm{~dB}$ was larger than $10 \mathrm{GHz}$ for composites of $2 \mathrm{~mm}$ in thickness. Especially, a minimum $\mathrm{R}=-58 \mathrm{~dB}$ was obtained at $11 \mathrm{GHz}$ for the composite containing $60 \mathrm{wt} \%$ of $\mathrm{Fe}(\mathrm{G})$, and a bandwidth of $\mathrm{R}<-10 \mathrm{~dB}$ was obtained from 7 to $18 \mathrm{GHz}$. Similarly, the $\mathrm{R}$ of the composite of $3 \mathrm{~mm}$ in thickness shifted towards low frequencies from 13 to $7 \mathrm{GHz}$ upon increasing the $\mathrm{Fe}(\mathrm{G})$ loading from $30 \mathrm{wt} \%$ to $60 \mathrm{wt} \%$. It is worth noting that the $\mathrm{Fe}(\mathrm{G}) /$ paraffin composite containing $60 \mathrm{wt} \%$ of $\mathrm{Fe}(\mathrm{G})$ and 2 and $3 \mathrm{~mm}$ in thickness exhibited $\mathrm{R}<-10 \mathrm{~dB}$ over the entire $\mathrm{X}(8-12 \mathrm{GHz})$ and $\mathrm{Ku}(12-18 \mathrm{GHz})$ bands. Thus, the $\mathrm{Fe}(\mathrm{G})$ composites prepared herein were suitable to broaden the bandwidth, and showed improved electromagnetic wave absorption properties.

As a result of the graphene shell outer protection, inner metallic particles with a size smaller than the skin-depth were isolated, enhancing the effective incidence to the electromagnetic wave absorbers [37]. Moreover, compared with some carbon-coated nanoparticle absorbents such as carbon-coated nickel [17,36], Fe(G) exhibited significantly wider bandwidth for electromagnetic absorption. The improved electromagnetic absorption performance of $\mathrm{Fe}(\mathrm{G})$ may result from the suitable complementarities between the dielectric and magnetic losses. We hypothesized that the 
compatibility between the graphene shell and the iron core increased the electromagnetic matching in the $\mathrm{Fe}(\mathrm{G})$ nanoparticles.

(a)

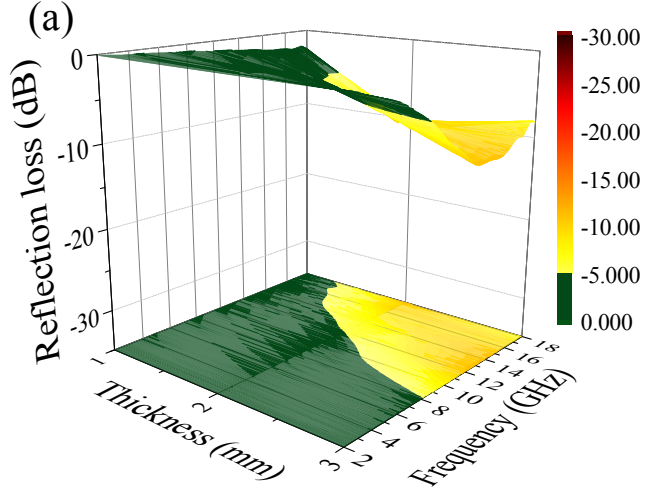

(c)

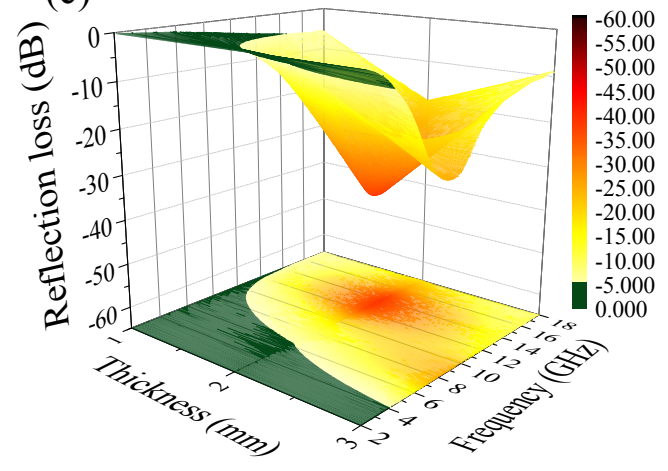

(b)

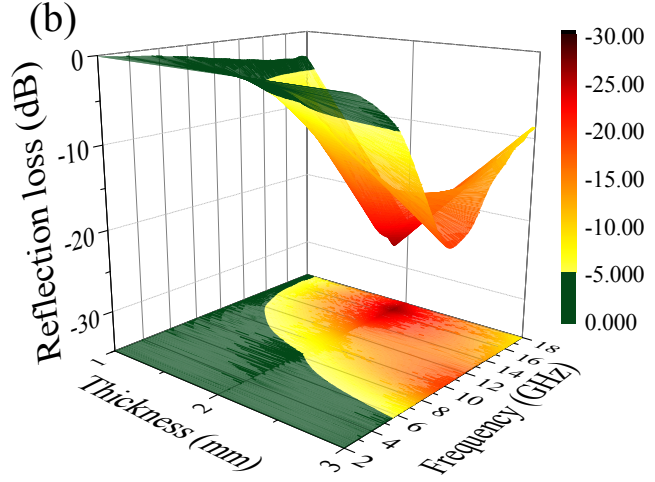

(d)

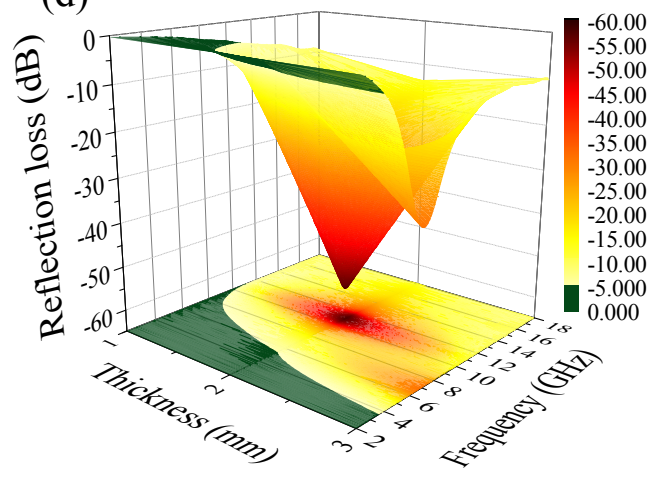

Figure 5. Frequency dependences of $\mathrm{R}$ for $\mathrm{Fe}(\mathrm{G}) /$ paraffin composites with $30 \mathrm{wt} \%$ (a), $40 \mathrm{wt} \%$ (b), $50 \mathrm{wt} \%(\mathbf{c})$, and $60 \mathrm{wt} \%$ (d) of $\mathrm{Fe}(\mathrm{G})$ and $1-3 \mathrm{~mm}$ in thickness under 2-18 GHz.

\subsection{Measured $R$ of the Fe(G)/Epoxy Coatings}

The $\mathrm{R}$ of an $\mathrm{Fe}(\mathrm{G}) /$ epoxy coating with a $60 \mathrm{wt} \% \mathrm{Fe}(\mathrm{G})$ loading and 1, 2, and $3 \mathrm{~mm}$ in thickness was measured and the results are shown in Figure 6 . The position of the $\mathrm{R}$ peak shifted towards lower frequencies and the minimum $\mathrm{R}$ decreased with the thickness of the material. For a $2 \mathrm{~mm}$ coating, we obtained a minimum $R$ value of $-22 \mathrm{~dB}$ at $11 \mathrm{GHz}$ and bandwidth of $\mathrm{R}<-10 \mathrm{~dB}$ was obtained for ca. 9-13 GHz. The positions of the minimum $\mathrm{R}$ were in line with the calculated results.

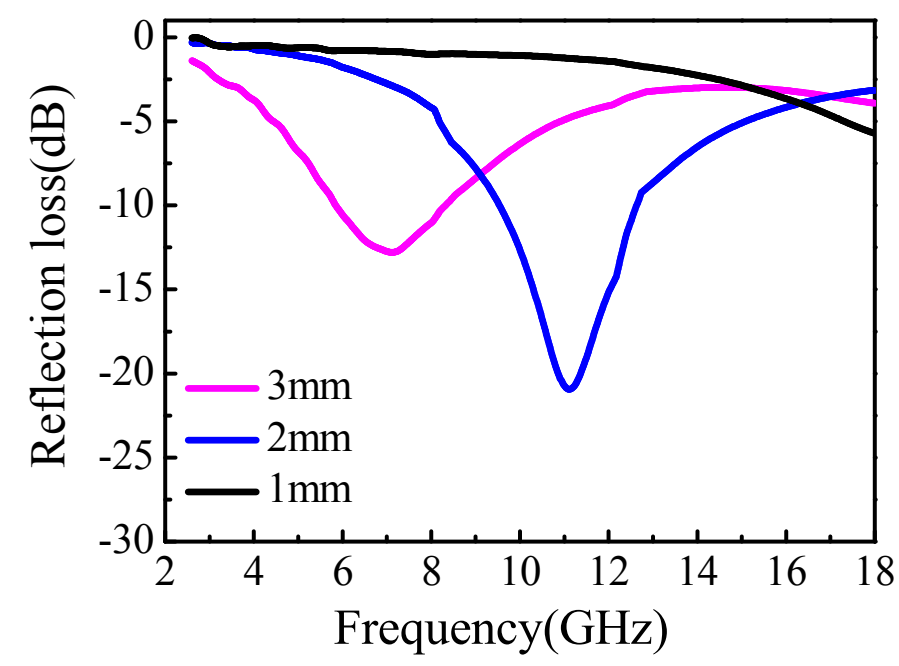

Figure 6. Measured $\mathrm{R}$ values for an $\mathrm{Fe}(\mathrm{G}) / \mathrm{epoxy}$ coating with $60 \mathrm{wt} \% \mathrm{Fe}(\mathrm{G})$ and 1, 2, and $3 \mathrm{~mm}$ in thickness. 


\section{Conclusions}

$\mathrm{Fe}(\mathrm{G})$ nanoparticles with a core of magnetic iron nanoparticles and a shell of dielectric graphene were prepared by an arc discharge method. The microstructure, phase, and composition of the $\mathrm{Fe}(\mathrm{G})$ were examined by TEM, XRD, Raman, and XPS. The Fe $(\mathrm{G})$ possessed a distinctive core-shell structure, with the inner crystal iron core being completely coated by the outer graphene shell, which consisted of 5-7 nm graphite layers. The major electromagnetic absorption mechanism was dielectric loss. The electromagnetic characteristics of the $\mathrm{Fe}(\mathrm{G})$ were investigated under $2-18 \mathrm{GHz}$, and the results showed that the $\varepsilon^{\prime}$ decreased with the frequency, while the opposite trend was found for $\varepsilon^{\prime \prime}$. $\varepsilon^{\prime}$ and $\varepsilon^{\prime \prime}$ both increased with the $\mathrm{Fe}(\mathrm{G})$ loading (30wt\%, $40 \mathrm{wt} \%, 50 \mathrm{wt} \%$, and $60 \mathrm{wt} \%$ ) at a fixed frequency. The dielectric loss was the main loss mechanism for the electromagnetic waves of the $\mathrm{Fe}(\mathrm{G})$. The calculated $\mathrm{R}$ showed a value of $-58 \mathrm{~dB}$ (bandwidth of $\mathrm{R}<-10 \mathrm{~dB}$ under $7-18 \mathrm{GHz}$ ) at $11 \mathrm{GHz}$ for the composite containing $60 \mathrm{wt} \% \mathrm{Fe}(\mathrm{G})$ and $2 \mathrm{~mm}$ in thickness. The results revealed that the electromagnetic absorption properties of the $\mathrm{Fe}(\mathrm{G})$ can be adjusted by optimizing both the concentration of $\mathrm{Fe}(\mathrm{G})$ and the coating thickness. The peak position of the measured $\mathrm{R}$ for an $\mathrm{Fe}(\mathrm{G}) / \mathrm{epoxy}$ coating with $60 \mathrm{wt} \% \mathrm{Fe}(\mathrm{G})$ showed good agreement with the calculated value. The $\mathrm{Fe}(\mathrm{G})$ nanoparticles prepared herein can be used as excellent electromagnetic absorption materials for 2-18 GHz radiations or even higher. The core-shell microstructure of the $\mathrm{Fe}(\mathrm{G})$ nanoparticles is of significant importance for establishing good electromagnetic match, dielectric loss, and magnetic loss. Both the theoretical and experimental results of the $\mathrm{Fe}(\mathrm{G})$ showed that this core-shell structure is very promising to prepare good electromagnetic absorption materials.

Supplementary Materials: The following are available online at http://www.mdpi.com/2079-4991/10/5/931/s1, Figure S1: C1s XPS spectra of the Fe(G) nanoparticles; Figure S2: Frequency dependences of R for a Fe(G)/paraffin composite with $40 \mathrm{wt} \%$ loading as compared with only graphene $(\mathrm{G})$ and only iron nanoparticles $(\mathrm{Fe})$ of $3 \mathrm{~mm}$ in thickness under 2-18 GHz.

Author Contributions: Conceptualization, D.Z. and H.Z. (Haiyan Zhang); methodology, D.Z.; software, Y.D.; validation, Y.D., C.H. and H.Z. (Haiping Zhu); formal analysis, C.Y.; investigation, Y.D.; resources, H.Z. (Haiyan Zhang); data curation, D.Z.; writing—original draft preparation, D.Z.; writing-review and editing, D.Z. and Y.D.; visualization, C.H.; supervision, H.Z. (Haiyan Zhang); project administration, H.Z. (Haiyan Zhang); funding acquisition, D.Z. All authors have read and agreed to the published version of the manuscript.

Funding: This research was funded by the Science and Technology Program of Guangzhou City of China (Grant No. 201803010071), and by the Science and Technology Program of Guangdong Province of China (Grant No. 2019A050510012, 2020A050515007).

Acknowledgments: This work was supported by Yun Zheng, the State Key Laboratory of Oncology in South China, Cancer Center of Sun Yat-sen University.

Conflicts of Interest: The authors declare no conflict of interest.

\section{References}

1. Zhang, Z.; Zhu, Q.; Chen, X.; Wu, Z.; He, Y.; Lv, Y.; Zhang, L.; Zou, Y. Ni@C composites derived from Ni-based metal organic frameworks with a lightweight, ultrathin, broadband and highly efficient microwave absorbing properties. Appl. Phys. Express 2018, 12, 011001. [CrossRef]

2. Chen, W.; Liu, Q.; Zhu, X.; Fu, M. One-step in situ growth of magnesium ferrite nanorods on graphene and their microwave-absorbing properties. Appl. Organomet. Chem. 2017, 32, e4017. [CrossRef]

3. Hosseini, H.; Mahdavi, H. Nanocomposite based on epoxy and MWCNTs modified with $\mathrm{NiFe}_{2} \mathrm{O}_{4}$ nanoparticles as efficient microwave absorbing material. Appl. Organomet. Chem. 2018, 32, e4294. [CrossRef]

4. Lv, H.; Yang, Z.; Wang, L.P.; Ji, G.; Song, J.; Zheng, L.; Zeng, H.; Xu, Z.J. A Voltage-Boosting Strategy Enabling a Low-Frequency, Flexible Electromagnetic Wave Absorption Device. Adv. Mater. 2018, 30, 1706343. [CrossRef] [PubMed]

5. Zhang, K.; Gao, X.; Zhang, Q.; Li, T.; Chen, H.; Chen, X. Preparation and microwave absorption properties of asphalt carbon coated reduced graphene oxide/magnetic $\mathrm{CoFe}_{2} \mathrm{O}_{4}$ hollow particles modified multi-wall carbon nanotube composites. J. Alloys Compd. 2017, 723, 912-921. [CrossRef] 
6. Zhang, X.; Ji, G.; Liu, W.; Quan, B.; Liang, X.; Shang, C.; Cheng, Y.; Du, Y. Thermal conversion of an $\mathrm{Fe}_{3} \mathrm{O}_{4}$ @metal-organic framework: A new method for an efficient Fe-Co/nanoporous carbon microwave absorbing material. Nanoscale 2015, 7, 12932-12942. [CrossRef] [PubMed]

7. Xiang, Z.; Song, Y.; Xiong, J.; Pan, Z.; Wang, X.; Liu, L.; Liu, R.; Yang, H.; Lu, W. Enhanced electromagnetic wave absorption of nanoporous $\mathrm{Fe}_{3} \mathrm{O}_{4} @$ carbon composites derived from metal-organic frameworks. Carbon 2019, 142, 20-31. [CrossRef]

8. Liu, L.; He, N.; Wu, T.; Hu, P.; Tong, G. Co/C/Fe/C hierarchical flowers with strawberry-like surface as surface plasmon for enhanced permittivity, permeability, and microwave absorption properties. Chem. Eng. J. 2019, 355, 103-108. [CrossRef]

9. Wu, N.; Liu, C.; Xu, N.; Liu, J.; Liu, W.; Shao, Q.; Guo, Z. Enhanced Electromagnetic Wave Absorption of Three-Dimensional Porous $\mathrm{Fe}_{3} \mathrm{O}_{4} / \mathrm{C}$ Composite Flowers. ACS Sustain. Chem. Eng. 2018, 6, 12471-12480. [CrossRef]

10. Lü, Y.; Wang, Y.; Li, H.; Lin, Y.; Jiang, Z.; Xie, Z.; Kuang, Q.; Zheng, L. MOF-Derived Porous Co/C Nanocomposites with Excellent Electromagnetic Wave Absorption Properties. ACS Appl. Mater. Interfaces 2015, 7, 13604-13611. [CrossRef]

11. Fukutsuka, T.; Yamaguchi, T.; Miyano, S.-I.; Matsuo, Y.; Sugie, Y.; Ogumi, Z. Carbon-coated stainless steel as PEFC bipolar plate material. J. Power Sources 2007, 174, 199-205. [CrossRef]

12. Guo, L.; Song, W.; Xie, C.; Zhang, X.; Hu, M. Characterization and thermal properties of carbon-coated aluminum nanopowders prepared by laser-induction complex heating in methane. Mater. Lett. 2007, 61, 3211-3214. [CrossRef]

13. Kang, Y.; Jiang, Z.; Ma, T.; Chu, Z.; Li, G. Hybrids of Reduced Graphene Oxide and Hexagonal Boron Nitride: Lightweight Absorbers with Tunable and Highly Efficient Microwave Attenuation Properties. ACS Appl. Mater. Interfaces 2016, 8, 32468-32476. [CrossRef] [PubMed]

14. Huang, Y.; Zhang, H.; Zeng, G.; Li, Z.; Zhang, D.; Zhu, H.; Xie, R.; Zheng, L.; Zhu, J. The microwave absorption properties of carbon-encapsulated nickel nanoparticles/silicone resin flexible absorbing material. J. Alloys Compd. 2016, 682, 138-143. [CrossRef]

15. Kang, D.; Kwon, J.Y.; Cho, H.; Sim, J.-H.; Hwang, H.S.; Kim, C.S.; Kim, Y.J.; Ruoff, R.S.; Shin, H.S. Oxidation Resistance of Iron and Copper Foils Coated with Reduced Graphene Oxide Multilayers. ACS Nano 2012, 6, 7763-7769. [CrossRef] [PubMed]

16. Zhang, X.F.; Guan, P.F.; Dong, X.L. Multidielectric polarizations in the core/shell Co/graphite nanoparticles. Appl. Phys. Lett. 2010, 96, 223111. [CrossRef]

17. Liu, X.G.; Li, B.; Geng, D.Y.; Cui, W.B.; Yang, F.; Xie, Z.G.; Kang, D.J.; Zhang, Z.D. (Fe, Ni)/C nanocapsules for electromagnetic-wave-absorber in the whole Ku-band. Carbon 2009, 47, 470-474. [CrossRef]

18. Han, Z.; Li, D.; Wang, H.; Liu, X.G.; Li, J.; Geng, D.; Zhang, Z.D. Broadband electromagnetic-wave absorption by $\mathrm{FeCo} / \mathrm{C}$ nanocapsules. Appl. Phys. Lett. 2009, 95, 23114. [CrossRef]

19. Han, D.; Or, S.W.; Dong, X.; Liu, B. FeSn 2 /defective onion-like carbon core-shell structured nanocapsules for high-frequency microwave absorption. J. Alloys Compd. 2017, 695, 2605-2611. [CrossRef]

20. Cheng, C. Solid-state optoelectronic device based on $\mathrm{TiO}_{2} / \mathrm{SnSe}_{2}$ core-shell nanocable structure. Opt. Mater. Express 2017, 7, 3691. [CrossRef]

21. Jian, X.; Chen, G.; Liu, H.; Mahmood, N.; Zhu, S.; Yin, L.; Tang, H.; Lv, W.; He, W.; Zhang, K.H.L.; et al. Vapor-Dissociation-Solid Growth of Three-Dimensional Graphite-like Capsules with Delicate Morphology and Atomic-level Thickness Control. Cryst. Growth Des. 2016, 16, 5040-5048. [CrossRef]

22. Jiang, Z.; Xiao, X.; Kuang, F.; Jian, X.; Rao, G.; Yin, L.; Liu, S.; Tian, W.; Mahmood, N.; Tan, Z. Mechanistic study of graphitic carbon layer and nanosphere formation on the surface of T-ZnO. Inorg. Chem. Front. 2017, 4, 978-985. [CrossRef]

23. Liu, L.; Das, A.; Megaridis, C.M. Terahertz shielding of carbon nanomaterials and their composites-A review and applications. Carbon 2014, 69,1-16. [CrossRef]

24. Wang, H.; Guo, H.; Dai, Y.; Geng, D.; Han, Z.; Li, D.; Yang, T.; Ma, S.; Liu, W.; Zhang, Z. Optimal electromagnetic-wave absorption by enhanced dipole polarization in Ni/C nanocapsules. Appl. Phys. Lett. 2012, 101, 083116. [CrossRef]

25. Lu, B.; Dong, X.; Huang, H.; Zhang, X.F.; Zhu, X.; Lei, J.; Sun, J. Microwave absorption properties of the core/shell-type iron and nickel nanoparticles. J. Magn. Magn. Mater. 2008, 320, 1106-1111. [CrossRef] 
26. Sun, Y.; Liu, X.; Feng, C.; Fan, J.; Lv, Y.; Wang, Y.; Li, C. A facile synthesis of FeNi3@C nanowires for electromagnetic wave absorber. J. Alloy. Compd. 2014, 586, 688-692. [CrossRef]

27. Liu, X.G.; Ou, Z.Q.; Geng, D.Y.; Han, Z.; Xie, Z.G.; Zhang, Z.D. Enhanced natural resonance and attenuation properties in superparamagnetic graphite-coated $\mathrm{FeNi}_{3}$ nanocapsules. J. Phys. D Appl. Phys. 2009, 42, 155004. [CrossRef]

28. Qin, F.; Brosseau, C. A review and analysis of microwave absorption in polymer composites filled with carbonaceous particles. J. Appl. Phys. 2012, 111, 061301. [CrossRef]

29. Liu, X.; Ou, Z.; Geng, D.; Han, Z.; Wang, H.; Li, B.; Brück, E.; Zhang, Z. Enhanced absorption bandwidth in carbon-coated supermalloy FeNiMo nanocapsules for a thin absorb thickness. J. Alloys Compd. 2010, 506, 826-830. [CrossRef]

30. Liu, X.; Ou, Z.; Geng, D.; Han, Z.; Jiang, J.; Liu, W.; Zhang, Z. Influence of a graphite shell on the thermal and electromagnetic characteristics of FeNi nanoparticles. Carbon 2010, 48, 891-897. [CrossRef]

31. Jian, X.; Wu, B.; Wei, Y.; Dou, S.; Wang, X.; He, W.; Mahmood, N. Facile Synthesis of $\mathrm{Fe}_{3} \mathrm{O}_{4} / \mathrm{GCs}$ Composites and Their Enhanced Microwave Absorption Properties. ACS Appl. Mater. Interfaces 2016, 8, 6101-6109. [CrossRef] [PubMed]

32. Guan, H.; Liu, S.; Duan, Y. Expanded Polystyrene as an Admixture in Cement-Based Composites for Electromagnetic Absorbing. J. Mater. Eng. Perform. 2007, 16, 68-72. [CrossRef]

33. Yan, S.; Xu, C.-Y.; Jiang, J.; Liu, D.; Wang, Z.; Tang, J.; Zhen, L. Strong dual-frequency electromagnetic absorption in $\mathrm{Ku}$-band of $\mathrm{C} @ \mathrm{FeNi}_{3}$ core/shell structured microchains with negative permeability. J. Magn. Magn. Mater. 2014, 349, 159-164. [CrossRef]

34. Micheli, D.; Apollo, C.; Pastore, R.; Morles, R.B.; Laurenzi, S.; Marchetti, M. Nanostructured composite materials for electromagnetic interference shielding applications. Acta Astronaut. 2011, 69, 747-757. [CrossRef]

35. Ismach, A.; Druzgalski, C.; Penwell, S.; Schwartzberg, A.M.; Zheng, M.; Javey, A.; Bokor, J.; Zhang, Y. Direct Chemical Vapor Deposition of Graphene on Dielectric Surfaces. Nano Lett. 2010, 10, 1542-1548. [CrossRef] [PubMed]

36. Zhang, X.F.; Dong, X.L.; Huang, H.; Liu, Y.Y.; Wang, W.N.; Zhu, X.G.; Lv, B.; Lei, J.; Lee, C.G. Microwave absorption properties of the carbon-coated nickel nanocapsules. Appl. Phys. Lett. 2006, 89, 053115. [CrossRef]

37. Xie, Z.; Geng, D.; Liu, X.; Ma, S.; Zhang, Z. Magnetic and Microwave-absorption Properties of Graphite-coated (Fe, Ni) Nanocapsules. J. Mater. Sci. Technol. 2011, 27, 607-614. [CrossRef]

38. Stankovich, S.; Dikin, D.A.; Piner, R.D.; Kohlhaas, K.A.; Kleinhammes, A.; Jia, Y.; Wu, Y.; Nguyen, S.T.; Ruoff, R.S. Synthesis of graphene-based nanosheets via chemical reduction of exfoliated graphite oxide. Carbon 2007, 45, 1558-1565. [CrossRef]

39. Liu, X.G.; Geng, D.; Meng, H.; Shang, P.J.; Zhang, Z.D. Microwave-absorption properties of ZnO-coated iron nanocapsules. Appl. Phys. Lett. 2008, 92, 173117. [CrossRef]

40. Feng, J.; Zong, Y.; Sun, Y.; Zhang, Y.; Yang, X.; Long, G.; Wang, Y.; Li, X.; Zheng, X. Optimization of porous $\mathrm{FeNi}_{3} / \mathrm{N}-\mathrm{GN}$ composites with superior microwave absorption performance. Chem. Eng. J. 2018, 345, 441-451. [CrossRef]

41. Liu, X.G.; Geng, D.; Meng, H.; Li, B.; Zhang, Q.; Kang, D.J.; Zhang, Z.D. Corrigendum: Fluorescence and microwave-absorption properties of multi-functional $\mathrm{ZnO}$-coated $\alpha$-Fe solid-solution nanocapsules. J. Phys. D Appl. Phys. 2012, 45, 239502. [CrossRef]

42. Zhang, X.F.; Dong, X.L.; Huang, H.; Lv, B.; Lei, J.P.; Choi, C.J. Microstructure and microwave absorption properties of carbon-coated iron nanocapsules. J. Phys. D Appl. Phys. 2007, 40, 5383-5387. [CrossRef]

43. Naito, Y.; Suetake, K. Application of Ferrite to Electromagnetic Wave Absorber and its Characteristics. In Proceedings of the G-MTT 1970 International Microwave Symposium, Newport Beach, CA, USA, 11-14 May 1970. [CrossRef]

(C) 2020 by the authors. Licensee MDPI, Basel, Switzerland. This article is an open access article distributed under the terms and conditions of the Creative Commons Attribution (CC BY) license (http://creativecommons.org/licenses/by/4.0/). 